Session 3268

\title{
Should Kinetics follow Kinematics? Only in the Dictionary!
}

\author{
Phillip J. Cornwell, Richard A. Layton \\ Rose-Hulman Institute of Technology
}

\begin{abstract}
The majority of dynamics textbooks are organized with an almost identical ordering of topics. This ordering is generally particle kinematics, particle kinetics, rigid body kinematics, rigid body kinetics, 3-D kinematics and kinetics and finally vibrations. There are a few textbooks that introduce more fully the concept of kinematics, including both particle and rigid body kinematics prior to the discussion of kinetics principles, but to the authors' knowledge no book starts with an extensive discussion of kinetics prior to kinematics. At Rose-Hulman Institute of Technology we have taken the approach of introducing the kinetics principles in the larger context of conservation principles, that is, conservation of mass, charge, linear momentum, angular momentum and energy using only very basic kinematics. Only after all of the kinetics principles are clearly understood are additional kinematics topics discussed. This approach is currently part of a sophomore curriculum where the concepts of conservation and accounting permeate a sequence of courses and assessment results indicate improved student learning. The purpose of this paper is to present a case for how and why a dynamics instructor teaching a conventional course might adopt this approach.
\end{abstract}

\section{Review of dynamics textbooks}

There are a large number of textbooks designed for use in introductory dynamics courses and the ordering of topics can be categorized in primarily two ways as shown in Table 1 . The books using Ordering \#1 as shown in Table 1 include those by Hibbeler ${ }^{1}$, Boresi and Schmidt ${ }^{2}$, Jong and Rogers ${ }^{3}$, Beer and Johnston ${ }^{4}$, Meriam and Kraige ${ }^{5}$, Sandor ${ }^{6}$, Shames ${ }^{7}$, Bedford and Fowler ${ }^{8}$, and Soutas-Little and Inman ${ }^{9}$. Although there are some variations among these books, for example, some include a chapter on systems of particles, their ordering of the topics is essentially identical. This ordering is: particle kinematics followed by particle kinetics followed by rigid body kinematics followed by rigid body kinetics. Ordering \#2 is used in the dynamics book by Riley and Sturges ${ }^{10}$. In this book kinematics, including both rigid body and particle kinematics, is presented prior to the discussion of kinetics principles. The authors are unaware of any books that begin with a discussion of kinetics prior to kinematics. The closest is the book by Pytel, Gosling, and Kiusalaas ${ }^{11}$. In this book the first chapter on particle dynamics integrates kinematics and kinetics. They state in the preface that "We found this arrangement superior to the traditional approach of devoting the opening chapter exclusively to kinematics. Introducing the student immediately to practical problems, where the equations of motion are derived and not given, provides a stronger motivation for learning." The authors agree with this statement, but would take it further. All of the kinetics principles should be discussed prior to an extensive discussion of kinematics! 
Table 1 - Conventional ordering of topics in introductory dynamics books.

\begin{tabular}{|c|c|}
\hline Ordering \#1 & Ordering \#2 \\
\hline $\begin{array}{l}\text { 1. Kinematics of a particle } \\
\text { 2. Kinetics of a particle (Newton's laws) } \\
\text { 3. Kinetics of a particle (work and energy) } \\
\text { 4. Kinetics of a particle (impulse and } \\
\text { momentum) } \\
\text { 5. Planar kinematics of a rigid body } \\
\text { 6. Planar kinetics of a rigid body (Newton's } \\
\text { laws) } \\
\text { 7. Planar kinetics of a rigid body (work and } \\
\text { energy) } \\
\text { 8. Planar kinetics of a rigid body (impulse and } \\
\text { momentum) } \\
\text { 9. Three dimensional kinematics of a rigid } \\
\text { body } \\
\text { 10. Three dimensional kinetics of a rigid body } \\
\text { 11. vibrations }\end{array}$ & $\begin{array}{l}\text { 1. Kinematics of particles } \\
\text { 2. Kinematics of rigid bodies } \\
\text { 3. Kinetics of particles (Newton's laws) } \\
\text { 4. Kinetics of rigid bodies (Newton's laws) } \\
\text { 5. Kinetics of particles (work and energy) } \\
\text { 6. Kinetics of rigid bodies (work and energy) } \\
\text { 7. Kinetics of particles (impulse and } \\
\text { momentum) } \\
\text { 8. Kinetics of rigid bodies (impulse and } \\
\text { 9. Vibrations }\end{array}$ \\
\hline
\end{tabular}

When examining the curricula of a variety of schools, the authors discovered that most schools require Newtonian physics prior to dynamics. Therefore, students have already been exposed to the basic kinetics principles used in dynamics, that is, Direct Application of Newton's $2^{\text {nd }}$ Law, Work-Energy Methods, and Impulse-Momentum Methods. It is the authors' opinion that students could learn dynamics better by building on this material they already know rather than pretending that this is their first exposure to this material (even though they may claim this and their apparent lack of knowledge confirms this.)

At Rose-Hulman Institute of Technology we have taken the approach of presenting the kinetics principles in the larger context of conservation principles, that is, conservation of mass, charge, linear momentum, angular momentum and energy. Initially only very basic kinematics are used, that is, the kinematics students have already learned in prior courses of Newtonian physics or calculus. "Conservation" in this sense is not limited to situations in which the energy or momentum of a system is constant, but is used to denote the more general definition of conservation of energy, linear momentum and angular momentum. Only after all of the kinetics principles are clearly understood are additional kinematics topics discussed. Applying the kinetics is what motivates the teaching of additional kinematics. This approach is currently part of a sophomore curriculum in which the concepts of conservation and accounting permeate a sequence of courses and assessment results indicate improved student learning. The details of 
how this approach is used at Rose-Hulman and how it could possibly be implemented in a single dynamics course is presented below.

\section{The Sophomore Engineering Curriculum (SEC) at Rose-Hulman}

A number of pedagogical techniques are being used to try to enhance the learning of dynamics. These include cooperative learning, simulation software such as Working Model, computer algebra systems such as Maple or MathCad, looking at a full range of motion rather than "static dynamics", concept questions, etc. All of these have been used at Rose-Hulman, and in the authors' opinion are beneficial for enhancing student learning. However, the only quantified improvement in student learning took place when an entirely new curriculum was implemented in $1995^{12-13}$. Rose-Hulman, as part of the NSF sponsored Foundation Coalition, implemented a new sophomore curriculum starting in the 1995-96 academic year. The sophomore year curriculum primarily concentrates on engineering science material that is traditionally covered in courses such as Dynamics, Thermodynamics I, Fluid Mechanics and Circuits I. Even though basic principles such as conservation of energy and conservation of linear and angular momentum are encountered in these courses, the notation and methodology are often such that the principles look different in different classes. Therefore, subsequent courses do not reinforce the material taught in previous courses. At Rose-Hulman this material has been repackaged into a new sequence of courses called the Sophomore Engineering Curriculum (SEC) as shown in Figure 1. One purpose of the curriculum is to teach engineering science in a more cohesive and internally consistent manner.

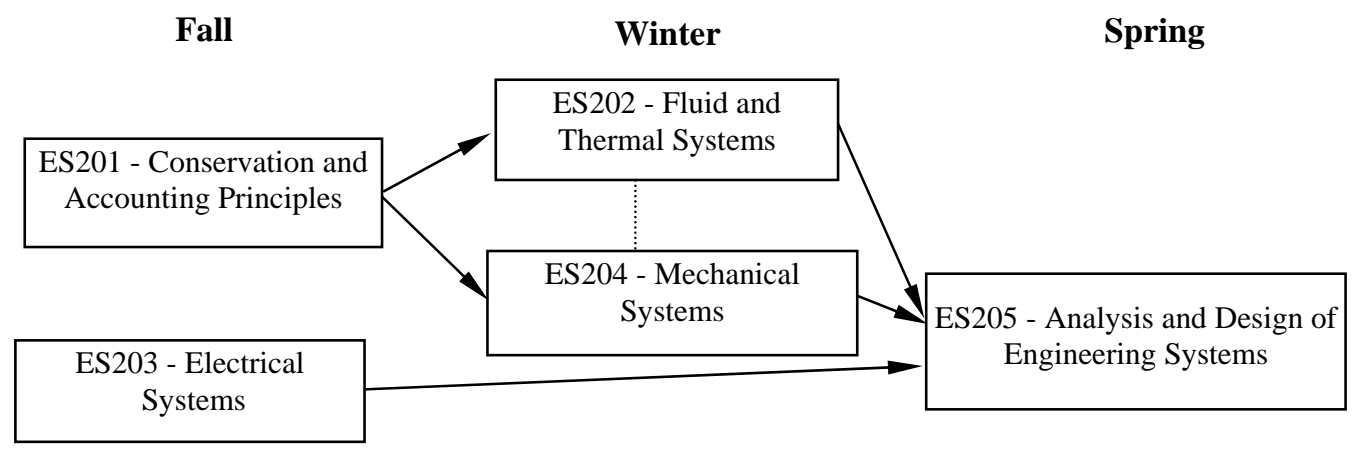

Figure 1 - Summary of the current sophomore engineering curriculum (SEC) at RoseHulman. A sequence of three courses can be used since Rose-Hulman is on the quarter system.

In the fall-quarter course Conservation and Accounting Principles (ES201), students are taught the basic principles for both open and closed systems. That is, we discuss conservation of mass, charge, linear momentum, angular momentum, and energy and the accounting of entropy. We also teach a problem solving methodology and homework format that is used in all subsequent courses. Electrical Systems (ES203) is also taught this quarter. In the winter quarter the students take two courses that build on ES201. These courses are Mechanical Systems and Fluid and Thermal Systems. In these courses the more detailed applications of the conservation principles are discussed as well as some of the additional topics required to solve problems such as 
properties in Fluid and Thermal Systems and kinematics in Mechanical Systems. Finally in the spring quarter the material is brought back into a single course called Analysis and Design of Engineering Systems (ES205) which is a system dynamics course in which multi-disciplinary problems are studied. There is also a lab associated with this course. Since material is distributed over a sequence of courses, it is frequently revisited and continually being reinforced at a higher cognitive level.

\section{Mechanics in the SEC}

In the first course, Conservation and Accounting Principles (ES201), much of particle dynamics is covered as applications of conservation of linear momentum, conservation of angular momentum, and conservation of energy. Approximately seven 50 minute lectures are used to discuss linear and angular momentum and three are used for the application of conservation of energy to mechanical systems. Topics not covered in the first course include inelastic impacts requiring introduction of the coefficient of restitution and most kinematics other than the basic relationships between position, velocity and acceleration. One significant difference, however, is that in ES201 the principles are applied to both open and closed systems, whereas in conventional dynamics the problems typically involve only closed systems. The rate forms for conservation of linear momentum, angular momentum and energy as presented in the course are listed in Table 2. The finite time forms of these principles are also discussed in the course. The finite time form for linear momentum for a closed system is applied to problems involving impacts and the finite time form for energy is applied to problems involving mechanical energy.

\begin{tabular}{|c|c|}
\hline \multicolumn{2}{|c|}{ Table 2 Basic mechanics principles (rate form) as presented in ES201 } \\
\hline Principle & Equation \\
\hline $\begin{array}{c}\text { Conservation of Linear Momentum } \\
\text { (rate form) }\end{array}$ & $\frac{d \vec{P}_{\text {sys }}}{d t}=\sum \vec{F}+\sum_{\text {in }} \dot{m}_{i} \vec{v}_{i}-\sum_{\text {out }} \dot{m}_{o} \vec{v}_{o}$ \\
\hline $\begin{array}{c}\text { Conservation of Angular Momentum } \\
\text { (rate form) }\end{array}$ & $\frac{d \vec{L}_{\text {sys }}}{d t}=\sum \vec{M}_{o}+\sum_{\text {in }} \vec{r}_{i} \times \dot{m}_{i} \vec{v}_{i}-\sum_{\text {out }} \vec{r}_{o} \times \dot{m}_{o} \vec{v}_{o}$ \\
\hline $\begin{array}{c}\text { Conservation of Energy } \\
\text { (rate form) }\end{array}$ & $\frac{d E_{s y s}}{d t}=\dot{Q}+\dot{W}+\sum_{\text {in }} \dot{m}_{i}\left(h+\frac{v^{2}}{2}+g z\right)_{i}-\sum_{\text {out }} \dot{m}_{o}\left(h+\frac{v^{2}}{2}+g z\right)_{o}$ \\
\hline
\end{tabular}

One feature of ES201 is that the course imparts both a clear understanding of how conservation of energy is applied in most thermodynamics applications (rate or finite time form for open and closed systems), dynamics applications (finite time form for adiabatic, closed systems) and fluids applications (rate form for an adiabatic open system). The way springs are handled is also clearer for the students. If the spring is inside the system then it is treated as an energy term and if it is outside the system then the work the spring force does needs to be calculated.

In the winter quarter course, Mechanical Systems (ES204), the basic principles introduced in ES201 are applied in more detail to dynamics problems. A consequence of all the kinetics 
principles being taught in ES201 is that in ES204 the material can be reordered so that as kinematics concepts are taught they can immediately be applied to kinetics problems, thereby motivating the kinematics and reinforcing the kinetics. For example, when normal and tangential coordinates are introduced for particles, problems involving kinetics can be solved. These problems may involve one or more of the conservation principles. Another advantage of this approach is that students are required to apply the kinetics principles "out-of-context". Typically in a dynamics course students know what principle to apply based on the topic currently being discussed in class. With this new arrangement of the material, students need to decide which conservation principle is most applicable thereby helping them practice at a higher level of cognitive learning as described by Bloom's Taxonomy of Cognitive Learning ${ }^{14}$.

In a traditional sophomore dynamics course, the primary kinetics principles used to solve problems are usually presented as 1) direct application of Newton's Second Law, 2) work-energy methods, and 3) impulse-momentum methods. In this curriculum these are presented as conservation of linear and angular momentum (rate and finite time forms) and conservation of energy (finite time form). A comparison of the terminology is shown in Table 3. This table is given to the students at the beginning of the course to help them relate the material in the text to the material learned in the previous course. In the course both sets of terminology are used.

Table 3 A comparison between the nomenclature used in Dynamics and the one used in Mechanical Systems

\begin{tabular}{|c|c|c|c|}
\hline Principle & ES201 Name & $\begin{array}{c}\text { Dynamics } \\
\text { Name }\end{array}$ & Comments \\
\hline $\begin{aligned} \frac{d \vec{P}_{s y s}}{d t} & =\sum \vec{F} \\
\frac{d \vec{L}_{\text {sys }_{0}}}{d t} & =\sum \vec{M}_{o}\end{aligned}$ & $\begin{array}{l}\text { Rate form for } \\
\text { conservation of } \\
\text { linear and } \\
\text { angular } \\
\text { momentum for a } \\
\text { closed system. }\end{array}$ & $\begin{array}{l}\text { Direct } \\
\text { application } \\
\text { of Newton’s } \\
2^{\text {nd }} \text { Law }\end{array}$ & $\begin{array}{l}\text { When to use: } \\
\text { - } \quad \text { want to find forces and/or accelerations } \\
\text { - } \quad \text { want to find velocities and/or distance } \\
\text { traveled (which can be found by } \\
\text { separating variables and integrating the } \\
\text { basic kinematic relationships) }\end{array}$ \\
\hline $\begin{array}{l}\Delta \vec{P}_{\text {sys }}=\int_{t_{1}}^{t_{2}} \vec{F} d t, \Delta \vec{L}_{\text {sys }_{0}}=\int_{t_{1}}^{t_{2}} \vec{M}_{0} d t \\
\text { or if there are impulsive loads } \\
\text { acting on the system } \\
\qquad \Delta \vec{P}_{\text {sys }}=\sum \vec{F}_{i} \Delta t, \\
\qquad \Delta \vec{L}_{\text {sys }_{0}}=\sum\left(\vec{M}_{0}\right)_{i} \Delta t \\
\text { where } \mathrm{F}_{\mathrm{i}} \text { and } \mathrm{M}_{\mathrm{i}} \text { are the external } \\
\text { impulsive forces and moments. }\end{array}$ & $\begin{array}{l}\text { Finite time form } \\
\text { of conservation } \\
\text { of linear and } \\
\text { angular } \\
\text { momentum for a } \\
\text { closed system. }\end{array}$ & $\begin{array}{l}\text { Impulse- } \\
\text { momentum } \\
\text { methods }\end{array}$ & $\begin{array}{l}\text { When to use: } \\
\text { - } \quad \text { have an impact or impulsive forces } \\
\text { - } \quad \text { the system consists of several objects } \\
\text { - } \quad \text { given a force as a function of time } \\
\text { - } \quad \text { want to find velocities, times, or forces } \\
\quad \text { (especially impulsive forces) }\end{array}$ \\
\hline$\Delta E_{\text {sys }}=W$ & $\begin{array}{l}\text { Finite time form } \\
\text { of conservation } \\
\text { of energy for an } \\
\text { adiabatic closed } \\
\text { system. }\end{array}$ & $\begin{array}{l}\text { Work- } \\
\text { energy } \\
\text { methods }\end{array}$ & $\begin{array}{l}\text { When to use: } \\
\text { - } \quad \text { have two locations in space } \\
\text { - } \quad \text { given a force as a function of position } \\
\text { - } \quad \text { want to find velocities, distances, or } \\
\quad \text { forces (sometimes) }\end{array}$ \\
\hline
\end{tabular}




\section{Assessment}

An important part of any new curriculum development effort is to assess the results to determine if the new curriculum is an improvement over the old, or, at the very least, produces roughly comparable results to the old curriculum. In order to assess the mechanics portion of the SEC, identical finals were given to students taking ES204 and students taking the traditional dynamics course. There were approximately 125 Dynamics students and 90 SEC students. Both finals consisted of 20 multiple-choice problems (40\% of the total points) and 3 workout problems (60\% of the total points). This format for the final has been used for many years in the dynamics course because it is felt that this is the best way to make the final comprehensive. A more complete discussion of the assessment can be found in Reference 12. As shown in this reference, improvements were seen in both the multiple choice problems and the workout problems, with the most profound difference being in the workout problems. A comparison of the results for the workout problem is shown in Table 4. For the purpose of Table 4 it was assumed that a student who got a perfect score or only missed one point on the workout problem essentially got the problem correct. To reduce the influence of a particular professor the numbers for Table 4 were obtained by averaging the results from five Dynamics sections (three professors) and from four Mechanical Systems (ES204) sections (three professors).

\begin{tabular}{|c|c|c|c|}
\hline \multicolumn{4}{|c|}{ Table 4 Percentage of students with correct answers for the work-out } \\
problems (1997-1998 academic year) \\
\hline $\begin{array}{c}\text { Workout } \\
\text { Problem }\end{array}$ & ES204 (SEC) & Dynamics Class & Difference \\
\hline 21 & 36.8 & 17.0 & 19.8 \\
\hline 22 & 70.1 & 22.0 & 48.1 \\
\hline 23 & 46.0 & 6.0 & 40.0 \\
\hline
\end{tabular}

The workout problems were in general designed to be longer, more difficult and required multiple steps and concepts. The three workout problems are shown in Figure 2. The students in the new curriculum did significantly better than those taking the traditional dynamics course. From this assessment it is clear that the new curriculum does not hurt the students and in fact it appears to help them in mastering the mechanics material.

For this assessment, the majority of students in the SEC were majors in electrical engineering (EE) and computer engineering (CO) and the students in the traditional dynamics course were mechanical engineering majors. Therefore, the question remained as to whether the students in the new curriculum performed better because the EE/CO students were academically superior to the ME students or because of the new curriculum. Since this curriculum was required for all mechanical engineering students beginning in the 1998-1999 academic year it has been possible to compare the performance of EE/CO and ME students taking identical courses. A summary of the distribution of final grades for ES201 is shown in Table 5. On average the mechanical engineering students actually performed better although it is not clear if the difference is statistically significant. Therefore, the authors feel confident that the improved performance of students as indicated in Table 4 can be attributed to the new curriculum rather than to the 
students' majors. Also, the mechanics material covered in E201 and ES204 is presented in about the same number of lectures that is used in a traditional dynamics course (10 lectures in ES201 and 27 lectures in ES204). The main difference is the ordering of the material and the presenting the kinetics concepts in a more general way, but no additional time was spent on the material.

\section{Problem 21}

A ball of mass $m$ and a radius $r$ is cast onto the horizontal surface such that it rolls without slipping. Determine the speed $\mathrm{V}_{\mathrm{G}}$ of it's mass center $\mathrm{G}$ so that it rolls without slipping completely around the loop of radius $\mathrm{R}+\mathrm{r}$ without leaving the track. $I_{G}=(2 / 5) \mathrm{mr}^{2}$. Express your answer in terms of radius $\mathrm{R}$ and the acceleration of gravity g. Hint: The velocity of the ball at the top of the circle is not zero.

\section{Problem 22}

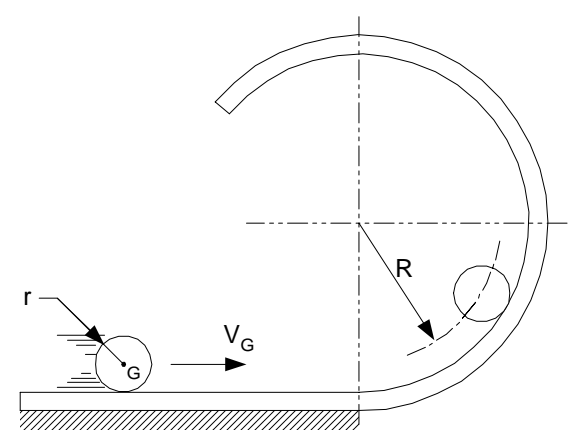

A cord is wrapped around the inner drum of a wheel and pulled horizontally with a force of $200 \mathrm{~N}$. The wheel has a mass of $50 \mathrm{~kg}$ and a radius of gyration of 0.07 $\mathrm{m}$. Let $\mu_{\mathrm{s}}=0.20$ and $\mu_{\mathrm{k}}=0.15$.

(a) Determine the friction force, $F$ at the wheel ground contact point assuming that the wheel rolls without slipping.

(b) Compare the friction force $F$ found in (a) to $F_{\max }$ and comment with respect to the rolling without slipping

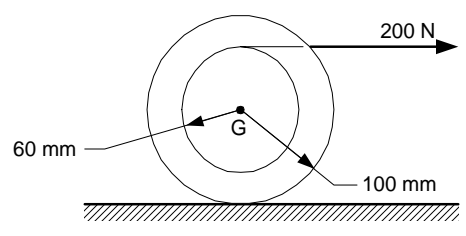
assumption.

\section{Problem 23}

A slender $12 \mathrm{ft}$. bar weighing $322 \mathrm{lbs}$. in the vertical plane is released from rest $1 \mathrm{ft} .6$ 5/8 in. above a firmly fixed peg $A$ in the position shown. The bar has a small hook attached at one end and arranged so that it will remain hooked to peg $A$ as it rotates. The rotating bar impacts another peg $B 8 \mathrm{ft}$. directly below peg $A$. The coefficient of restitution between peg $B$ and the bar is 0.4 . What is the bar's angular speed just after impact with peg $\boldsymbol{B}$ ? (Hint: Energy is lost when the hook hits peg A.)

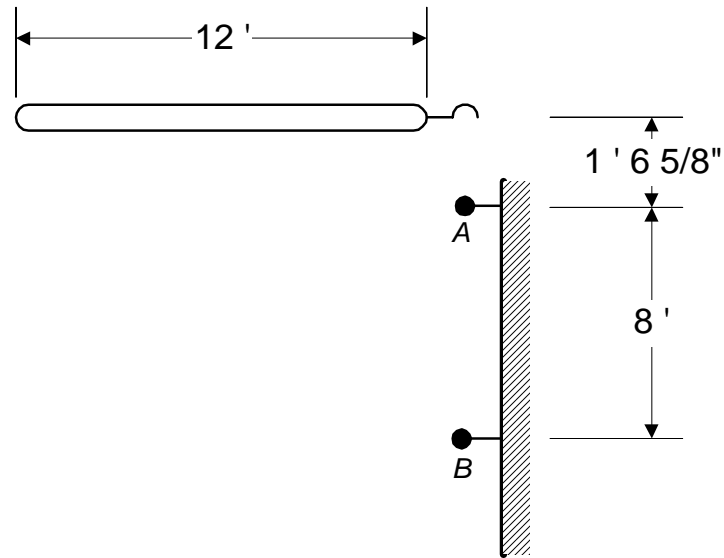

Figure 2 - Work out problems for final exam. The exam consisted of 20 multiple choice questions and these three workout problems (1997-1998 academic year). 


\begin{tabular}{|c|c|c|}
\hline \multicolumn{2}{|c|}{ Table 5 Grade distribution for ES201 by major } \\
\hline \multirow{2}{*}{ Grade } & \multicolumn{2}{|c|}{ Major } \\
\cline { 2 - 3 } A & EE/CO & ME \\
B+ & 10 & 9 \\
B & 24 & 10 \\
C+ & 21 & 25 \\
C & 22 & 19 \\
D+ & 7 & 8 \\
D & 10 & 6 \\
F & 2 & 7 \\
\hline Average GPA & 2.46 & 5 \\
\hline
\end{tabular}

\section{How to implement these ideas into a single dynamics course}

These assessment results and the Rose-Hulman sophomore curriculum have been discussed at a large number of conferences and yet no schools, to our knowledge, have attempted to duplicate our efforts. One possible reason for this is the difficulty associated with getting faculty who teach fluids, thermodynamics, electrical engineering and dynamics all to agree to an entirely new approach to teaching these subjects. The small size of Rose-Hulman and the emphasis on teaching and undergraduate education probably is what enabled us to make such a change. If it is not practical for other schools to implement a new curriculum, is it possible for individual faculty to revamp their own courses to include many of the concepts and ideas of the curriculum? It is the authors' opinion that this indeed may be possible and it is our hope that this paper will inspire some brave soul to attempt such an endeavor. The total number of 50 -minute lectures devoted to dynamics in the SEC is approximately 37. These lectures do not include 3-D kinematics, 3-D dynamics or vibrations, but it is not clear how many dynamics courses actually spend much time on these topics anyway. For this reason, it is felt that the arrangement of the material could be used in either a 30 or 40 lecture quarter course or a 45 lecture semester course. It would be easy to include 3-D kinematics and dynamics since no modification of the methodology would be required since the principles are still exactly the same. The only thing the students would need to be taught is 3-D kinematics and how the left-hand-side of $\frac{d \vec{L}_{\text {sys }_{0}}}{d t}=\sum \vec{M}_{o}$ is determined.

In the first few years of this curriculum a traditional dynamics book was used. The major advantage associated with this is that it was a good book with a good variety of problems and it exposed the students to the more traditional nomenclature and terminology associated with dynamics. The major disadvantage was that we jumped around in the book a tremendous amount and the book did not take advantage of the unified approach we were emphasizing in the curriculum. It was eventually decided that a new book for the course was to be developed. This book was written and is currently being used in the course. The table of contents is shown in Table 6. The topics covered in ES201 are primarily in Chapter 2 and the topics covered in ES204 are in chapters 3 and 4. Note that Chapter 2 beings with basic kinematics only and the 
kinematics associated with relative motion, dependent motion, and different coordinate systems are not introduced until Chapter 3, after all the kinetics principles are taught.

\section{Table 6 Table of contents of book used for ES204}

Chapter 1 Introduction

1.1 A bit of history

1.2 An overview of the class

1.3 The general problem solving methodology

Chapter 2 Review of Conservation Principles and Basic Kinematics

2.1 Basic Kinematics

2.2 Conservation of Linear Momentum (general comments)

- What is linear momentum?

- How do you calculate the linear momentum of a system of particles?

- How can linear momentum be transported?

- How can linear momentum be generated or destroyed?

2.3 Conservation of Linear Momentum (Rate Form)

2.3.1 Procedure for applying the rate form of conservation of linear momentum (Newton's $2^{\text {nd }}$ law) to particles 2.3.2 Frictional forces

2.4 Conservation of Linear Momentum (Finite Time)

2.4.1 Procedure for applying the conservation of linear momentum (finite time form) to particles

2.4 Conservation of Angular Momentum

- What is angular momentum?

- How do you calculate the angular momentum of a system of particles?

- How can angular momentum be transported into or out of a system?

- How can angular momentum be generated or destroyed?

- Modeling Reactions at Supports and Connections

2.5 Conservation of Energy

- Mechanical Work

- Mechanical Power

- Conservation of Energy from Conservation of Linear Momentum

- Elastic Potential Energy

2.6 Summary of the Conservation Principles to be Used

2.6.1 Procedure for applying the rate form of conservation of linear momentum (Newton's $2^{\text {nd }}$ law) to particles

2.6.2 Procedure for applying the finite time form of conservation of energy to particles

2.6.3 Procedure for applying the conservation of linear momentum (finite time form) to particles

Problems

Chapter 3 Particle Kinematics and Dynamics

3.1 Relative Motion

3.2 Dependent Motion

3.3 Different Coordinate Systems

3.3.1 Cartesian Coordinates

3.3.2 Normal and Tangential Coordinates

3.3.3 Radial and Transverse Coordinates

3.3.4 Summary of Different Coordinate Systems

3.4 Impact

3.4.1 Comments on the coefficient of restitution

Problems

Chapter 4 - Rigid-Body Dynamics

4.1 Introduction

4.2 Translation

4.3 Rigid-Body Rotation

4.3.1 Basic Kinematic Relationships

4.3.2 Fixed Axis Rotation

Proceedings of the 2005 American Society for Engineering Education Annual Conference \& Exposition

Copyright (C) 2005, American Society for Engineering Education 
\begin{tabular}{|l|}
\hline 4.3.3 Comments on applying the conservation principles \\
4.3.4 Rigid-Body Impact \\
4.4 General Plane Motion \\
4.4.1 Velocity \\
4.4.2 Instantaneous Center of Velocity \\
4.4.3 Accelerations \\
4.5 Rotating Axis \\
Problems \\
Appendix A - Mass Moments of Inertia
\end{tabular}

Engineering educators interested in trying this approach may request a free copy of this book and may distribute it to their students. The authors would also be willing to share their course notes. A copy of the textbook can be downloaded from:

http://www.rose.hulman.edu/ cornwell/courses/es204/Mechanical_Systems_Book.pdf.

A lesson plan for a one-semester course with suggested reading using a more traditional textbook is shown in Table 7. The readings were chosen from Beer and Johnston ${ }^{4}$. The schedule shown in Table 7 is very similar to what was used before textbooks were developed for ES201 and ES204. Even though a traditional textbook was used, many problems were written or modified by the instructors as indicated by the "P1", "P2", etc. in Table 7. As mentioned earlier, the authors tried using a well known (and well written) dynamics textbook, but students found the continual jumping around in the textbook frustrating. For example, the reading may be from chapter 11, but the problems assigned may be from chapters 12 and 13.

Table 7 Possible reading and homework assignments for a dynamics course in which all the kinetics principles are used before any detailed discussion of kinematics.

\begin{tabular}{|c|l|l|l|}
\hline Lecture & Topic & Reading & Homework \\
\hline 1 & Introduction of Conservation Principles & Handout & P1, P2 \\
\hline 2 & Linear Momentum - Conservation Principle, Basic Kinematics & $11.2,12.1-12.5$ & $14.58,68,11.191$ \\
\hline 3 & Linear Momentum - Examples & & $13.38,13.137$ \\
\hline 4 & Linear Momentum - Friction Examples & & $12.17, \mathrm{P} 3$ \\
\hline 5 & Linear Momentum - Impact & $13.9-13.11$ & $13.147,148,154$ \\
\hline 6 & Angular Momentum - Conservation Principle & Handout, 15.2 & $14.68, \mathrm{P} 4$ \\
\hline 7 & Angular Momentum - Translation & 15.2 & $16.3,16.10$ \\
\hline 8 & Examples & & $\mathrm{P} 5, \mathrm{P} 6$ \\
\hline 9 & Energy - Work-Energy Principle & $13.1-13.4$ & $13.14, \mathrm{P} 7$ \\
\hline 10 & Energy - Conservation Principle & Handout & $\mathrm{P} 8, \mathrm{P} 9$ \\
\hline 11 & Energy - Conservation Principle & & $\mathrm{P} 10, \mathrm{P} 11$ \\
\hline 12 & Review & & \\
\hline 13 & EXAM 1 & & \\
\hline
\end{tabular}

Proceedings of the 2005 American Society for Engineering Education Annual Conference \& Exposition Copyright (C) 2005, American Society for Engineering Education 


\begin{tabular}{|c|c|c|c|}
\hline 14 & Kinematic Relationships, Relative Motion & 11.1-6,11.12 & $12.27,11.121,127$ \\
\hline 15 & Relative Motion, Dependent Motion & 11.6 & $12.28,12.33$ \\
\hline 16 & Normal and Tangential Coordinates & 11.13 & $12.46,13.44,73$ \\
\hline 17 & Radial and Transverse Coordinates & 11.14 & $11.163,193,12.72$ \\
\hline 18 & Impact, Coefficient of Restitution & 13.13-14 & $13.159,178,185$ \\
\hline 19 & Impact & & 13.187, 13.C5 \\
\hline 20 & Translation & 15.1-2,16.1-4 & $16.3,16.17$ \\
\hline 21 & Kinematics, Fixed axis rotation & $15.3-4$ & $15.6,10,30$ \\
\hline 22 & Fixed axis rotation & & $16.43,90,17.16$ \\
\hline 23 & Review & & \\
\hline 24 & EXAM 2 & & \\
\hline 25 & Instantaneous Centers & $15.5-7$ & $15.81,15.82$ \\
\hline 26 & Velocity-Vector Approach & & $17.43,17.47$ \\
\hline 27 & Energy Examples & & $17.19,32$ \\
\hline 28 & Momentum Examples & 17.8 & $17.95,96$ \\
\hline 29 & Momentum Examples & & $17.115,117$ \\
\hline 30 & Kinematics, Acceleration & & 15.108,111, P12 \\
\hline 31 & Kinematics, Linkages & & 15.126,15.130 \\
\hline 32 & Kinetics & & $16.48,16.62$ \\
\hline 33 & Kinetics, Rolling & & $16.70,16.105$ \\
\hline 34 & Kinetics, General Plane Motion & & P13, P14 \\
\hline 35 & Review & & \\
\hline 36 & EXAM 3 & & \\
\hline 37 & Rotating Axes & $15.10-15.11$ & 15.12915 .133 \\
\hline 38 & Rotating Axes & & 15.137, P15 \\
\hline 39 & Rotating Axes & & P16, P17 \\
\hline 40 & Review, Evaluations & & \\
\hline
\end{tabular}

To the brave dynamics instructor considering teaching kinetics before kinematics we offer the following advice: First, consider using the ES204 text developed at Rose-Hulman to reduce student frustration associated with jumping around in a textbook. If this is not possible because you either do not like the book or because it is important to use the same textbook as colleagues at your institution we suggest you rearrange the material as suggested in Table 7 . Thus, by the first exam, students will already have been taught the three kinetics principles: The rate form of conservation of linear and angular momentum (direct application of Newton's $2^{\text {nd }}$ law), the finite time form of linear and angular momentum (impulse-momentum methods), and conservation of energy for a closed, adiabatic system (work-energy methods). Second, after students have 
experience with all of these principles it is important to have multi-concept problems and problems involving these principles "out of context", for the remainder of the course.

\section{Conclusions}

At Rose-Hulman the mechanics material traditionally taught in a dynamics course has been distributed throughout a sequence of three courses and taught within a framework of conservation and accounting. One significant difference in the sequencing of mechanics material in this curriculum is that the kinetics principles are introduced prior to any significant discussion of kinematics. Assessment results indicate an improved performance by students in the new curriculum over students taking the traditional dynamics course. In this paper suggestions were made on how the same ordering of topics could be used in a traditional dynamics course. There would not be the advantage of distributing the material over a sequence of courses, but there still may be some benefit to be derived by introducing all the kinetics principles first prior to any detailed discussion of kinematics.

\section{References}

1. Hibbeler, R.C., Engineering Mechanics: Dynamics, $9^{\text {th }}$ Edition, Prentice-Hall, Inc., 2001.

2. Boresi, A.P., R.J. Schmidt, Engineering Mechanics: Dynamics, Brooks/Cole, 2000.

3. Jong, I.C., B.G. Rogers, Engineering Mechanics Dynamics, Oxford University Press, 1997.

4. Beer, P.B. and E.R. Johnston, Vector Mechanics for Engineers: Dynamics, $6^{\text {th }}$ Edition, McGraw-Hill, 1999.

5. Meriam, J.L., and L.G. Kraige, Engineering Mechanics, Dynamics, $5^{\text {th }}$ Edition, John Wiley \& Sons, Inc., 2002.

6. Sandor, B.I., Engineering Mechanics Dynamics, $2^{\text {nd }}$ Edition, Prentice-Hall, Inc., 1987.

7. Shames, I.H., Engineering Mechanics Dynamics, $4^{\text {th }}$ Edition, Prentice Hall, Inc. 1997.

8. Bedford, A, and W. Fowler, Engineering Mechanics: Dynamics, $3^{\text {rd }}$ Edition, Addison-Wesley, 2003.

9. Soutas-Little, R.W., and D.J. Inman, Engineering Mechanics: Dynamics, Prentice-Hall, 1999.

10. Riley, W.F., and L.D. Sturges, Engineering Mechanics: Dynamics, John Wiley \& Sons, Inc., 1993.

11. Pytel, A., and J. Kiusalaas, Engineering Mechanics Dynamics, $2^{\text {nd }}$ Edition, Brooks/Cole Publishing, 2001.

12. Cornwell, P.J. and J.M. Fine, “Integrating Dynamics throughout the Sophomore Year," 1999 ASEE Annual Conference Proceedings, Atlanta, June 1999.

13. Cornwell, P.J., "Dynamics Evolution - Chance or Design,” Proceedings of the 2000 ASEE Annual Conference, St. Louis, June 2000.

14. Bloom, B.S. (Ed.), “A Taxonomy of Educational Objectives: The Classification of Educational Goals. Handbook 1. The Cognitive Domain,” New York: McKay, 1956.

\section{PHILLIP CORNWELL}

Phillip Cornwell is a Professor of Mechanical Engineering at Rose-Hulman Institute of Technology. He received his Ph.D. from Princeton University in 1989 and his present interests include structural dynamics, structural health monitoring, and undergraduate engineering education. Dr. Cornwell has received an SAE Ralph R. Teetor Educational Award in 1992, and the Dean’s Outstanding Teacher award at Rose-Hulman in 2000.

\section{RICHARD LAYTON}

Richard Layton received his Ph.D. from the University of Washington in 1995 and is currently an Assistant Professor of Mechanical Engineering at Rose-Hulman. Prior to his academic career, Dr. Layton worked for twelve years in consulting engineering, culminating as a group head and a project manager. He is a member of the Teaching Workshop Group of the ERM Division of ASEE, giving workshops on building student teams. 